\title{
Essential Newborn Care Service Readiness and Barriers in Northwest Ethiopia: A Descriptive Survey and Qualitative Study
}

This article was published in the following Dove Press journal:

Journal of Multidisciplinary Healthcare

\author{
Tadesse Guadu Delele (D) \\ Gashaw Andargie Biks $\mathbb{D}^{2}$ \\ Solomon Mekonnen Abebe ${ }^{3}$ \\ Zemene Tigabu Kebede $\mathbb{1 D}^{4}$
}

'Department of Environmental and Occupational Health and Safety, Institute of Public Health, College of Medicine and Health Sciences, University of Gondar, Gondar, Ethiopia; ${ }^{2}$ Department of Health System and Policy, Institute of Public Health, College of Medicine and Health Sciences, University of Gondar, Gondar, Ethiopia; ${ }^{3}$ Departments of Human Nutrition, Institute of Public Health, College of Medicine and Health Sciences, University of Gondar, Gondar, Ethiopia; ${ }^{4}$ Department of Pediatrics and Child Health, School of Medicine, College of Medicine and Health Sciences, University of Gondar, Gondar, Ethiopia
Correspondence: Tadesse Guadu Delele Department of Environmental and Occupational Health and Safety, Institute of Public Health, College of Medicine and Health Sciences, University of Gondar, P.O. Box 196, Gondar, Ethiopia Email tadeguade2@gmail.com
Background: Despite the efforts put forth in improving neonatal survival, there is still a high rate of neonatal morbidity and mortality in northwest Ethiopia. Therefore, this study aimed to determine the essential newborn care service readiness scores and explore the health facility-related barriers in North Gondar Zone, Northwest Ethiopia.

Methods: A cross-sectional survey of 16 health facilities (14 health centers and two hospitals) and twelve in-depth interviews were included in the study in three randomly selected districts of North Gondar Zone. A pretested health facility inventory questionnaire customized from the World Health Organization (WHO) service readiness assessment tool was used for a facility audit. Basic emergency and essential obstetric and newborn care (BEmONC), and child immunization service readiness scores were determined using unweighted averages according to the WHO guideline. Descriptive statistics were done for the quantitative data, and thematic content analysis was employed using NVivo 12 software for the qualitative data.

Results: All the surveyed health facilities had no specialist medical doctors, and $50 \%(8 / 16)$ of them had no inpatient beds. The overall BEmONC service readiness score was $62.7 \%(10 /$ 16) $(95 \%$ CI: $34.8,83.8)$ and only one facility had all the tracer items. Trained staff and guidelines had a $27.5 \%(4 / 16)$ readiness score, followed by $71.9 \%(12 / 16)$ readiness score for equipment, and $88.6 \%(14 / 16)$ readiness score for medicine and commodities. The overall child immunization service readiness score was $90.3 \%(15 / 16)(95 \%$ CI: $51.4,94.7)$ and eleven facilities $(68.8 \%)$ had all the tracer items. The immunization service readiness score was higher; $84.4 \%(14 / 16)$ for trained staff and guidelines, $92.8 \%(15 / 16)$ for equipment, and $93.8 \%(15 / 16)$ for medicines and commodities. Unavailability of equipment, shortage of supplies, and lack of respectful and compassionate healthcare practices were the key facilityrelated barriers compromising essential newborn care service readiness.

Conclusions for Practice: The survey revealed that the essential newborn care service readiness score of the health facilities was low, and it calls for improving BEmONC service readiness in particular. Provision of timely training for newly recruited staff, fulfilling essential equipment, and steady supply is imperative.

Keywords: basic emergency, essential obstetric, newborn care, immunization, service readiness, barriers

\section{Background}

Neonatal mortality is a major public health problem worldwide. The global number of neonatal death was 2.5 million in 2018, which were $47 \%$ of all under-five deaths and this figure has increased from $40 \%$ in $1990 .{ }^{1}$ In Ethiopia, the neonatal mortality rate decreased from 39 to 30 per 1000 live births from 2005 to 2019 in contrast its 
share in under-five mortality has increased from $31 \%$ to $55 \%$. Moreover, neonatal mortality has remained stable since $2016 .^{2}$

The health facility readiness for essential newborn care service is vital for increasing access to quality neonatal care, ${ }^{3}$ increasing utilization of newborn care services, ${ }^{4}$ and ultimately increases neonatal survival. ${ }^{5}$ The health facility readiness for essential newborn care also indicates health system readiness to manage delivery and childbirth complications. ${ }^{6}$ A study has shown that proper essential newborn care services would reduce up to $85 \%$ of neonatal deaths annually. ${ }^{7}$

Newborn care is one of the components among the prior agendas of Ethiopia in the second Growth and Transformation Plan (GTP). ${ }^{8}$ The government is continuously strengthening the health facility readiness for essential newborn care services through a three-tier healthcare delivery system. The first tier comprising primary (district) hospital, health centers, and their satellite health posts connected by a referral system. The second tier is a general hospital serving a population of 1 to 1.5 million people, and the third level is a specialized hospital serving a population of 3.5 to 5 million people. ${ }^{9}$

In Ethiopia, $55 \%$ of the health facilities, excluding health posts provided, the delivery service. The mean readiness level of the tracer items to provide BEmONC service was $68 \%$ and none of these facilities had all the tracer items. ${ }^{10}$ However, there is a shortage of evidence to measure the readiness level and barriers of essential newborn care services among health facilities in Northwest Ethiopia.

Despite the efforts made in improving neonatal outcomes, there is still a high rate of neonatal morbidity and mortality in Ethiopia, and Northwest Ethiopia in particular. A recent study finding revealed that the incidence of neonatal morbidity and the case fatality rate were found to be $27.8 \%$ and $14.9 \%$, respectively among health facility deliveries in Northwest Ethiopia. ${ }^{11}$ Facility readiness and quality of care are among the major transformation agendas in Ethiopia, assessing the readiness level and barriers to health facilities is crucial to capture a selected set of data and triangulate various sources to improve the accuracy of health interventions. But, little is known regarding the current readiness level of health facilities to provide appropriate essential newborn care services in Northwest Ethiopia. Hence, this study aimed to fill this gap by determining the current essential newborn care service readiness score and exploring the health facility-related barriers in Northwest Ethiopia. The findings were important in planning intervention programs to improve the survival of neonates in the study area and other similar settings.

\section{Methods}

\section{Study Setting and Context}

This health facility survey and in-depth interview were conducted among health facilities providing delivery services in North Gondar Zone, Northwest Ethiopia. This administrative zone is structured in six districts and two city administrations. Debark city, which is the capital of the zone, is 820-kilo meters away from Addis Ababa. According to the Central Statistical Agency (CSA), the area has an estimated total population of 887,869 individuals, 37 health facilities providing delivery services (two hospitals and 35 health centers), and 1230 healthcare workers in $2016 / 17 .^{12}$ The survey was done in March 2019.

\section{Selection of the Health Facilities and Key Informants}

First, three districts were randomly selected (Dabat, Debark, and Janamora districts) out of eight in the North Gondar administrative zone. Then, the facility audit was done in all the 16 health facilities providing delivery services in the three randomly selected districts. Two district hospitals and 14 health centers were included in the survey.

To have an in-depth understanding of the health facility-related barriers for essential newborn care services, 12 key informant interviews (KII) were conducted with Maternal and Child Health (MCH) focal persons, Expanded Programme on Immunization (EPI) focal persons, and senior $\mathrm{MCH}$ experts in six health facilities. Key informants were selected purposely based on their close relationship with neonates and assumed to be rich sources of information on the research in question, and at least two interviews were included per facility. The number of KII was determined based on the level of saturation.

\section{Study Design and Data Collection}

A cross-sectional survey was done to collect health facility data on the essential newborn care services readiness scores in Northwest Ethiopia. A health facility inventory questionnaire customized from the WHO service readiness assessment tool ${ }^{13}$ was used to collect quantitative data. An explorative study was employed to explore the health 
facility-related barriers to the uptake of essential newborn care services.

Pretesting of the survey questionnaire was done outside the study area and adjustments were made. Data were collected by two trained first-degree nurses under the supervision of the investigators. The data collectors used observation checklists of the essential items to determine the availability and the functionality of equipment, medicines, and commodities for BEmONC and child immunization. Then, data was extracted from the District Health Information Software $\left(\mathrm{DHIS}_{2}\right)$ register of the included health facilities. The consistency and completeness of the data were regularly checked by supervisors (a clinician and researchers) throughout the entire data collection period.

Initially, the survey questionnaire was prepared in English. This survey questionnaire was translated into the local language, Amharic, and back to English by translators who were bilingual and competent in the two languages to check the content validity.

Before the commencement of the study, ethical clearance was secured from the Institutional Review Board (IRB) of the University of Gondar (UoG), and permission letters were secured from each district health institution's officials. To ensure confidentiality, codes were used for each health facility and interviewee.

\section{Measurements}

Essential newborn care is a set of practices provided by healthcare workers and mothers to every newborn during delivery. ${ }^{5}$

Essential newborn care service readiness refers to the presence of essential infrastructure, functioning equipment, supplies, medicines that are in-stock and nonexpired, trained staff, and current guidelines to provide the services. ${ }^{13}$ BEmONC and child immunization services readiness scores were determined using the three domains (trained staff and guidelines, equipment, and medicines and commodities). Readiness indices were calculated using unweighted averages based on the WHO guideline. BEmONC and child immunization service readiness scores were equal to the sum of the means that were obtained for each tracer item in each domain, divided by the total number of items in the domain, and then multiplied by 100 .

\section{Data Management and Analysis}

The survey data collected on the paper were entered and cleaned using the Epi-Info version 7.1.5.0 software.
Cleaning was made for accuracy, completeness, and consistency. The cleaned data were exported to STATA version 14 software to determine the service readiness scores. Descriptive statistics were used to determine the readiness score indices and chi-square tests were used to compare categorical variables.

The qualitative data were transcribed and translated from Amharic into the English language. Then, codes were identified and tallied to come up with some categories, which were later used to establish themes. Finally, thematic content analysis was done using NVivo 12 software and the findings were triangulated with the quantitative findings.

\section{Results}

\section{Characteristics of the Health Facilities}

Among the 16 health facilities included in this survey; $87.5 \%(14 / 16)$ were health centers, $62.5 \%(10 / 16)$ of them provided inpatient services, and half of them had no inpatient beds. All facilities lack specialist medical doctors and only hospitals had generalist medical doctors. The mean number of outpatient visits per year was 6970 for health centers and 44,507 for hospitals (Table 1).

\section{BEmONC Services Readiness Score}

The overall BEmONC service readiness score was $62.7 \%$ (10/16), and only one health facility had all the tracer items in the three domains (trained staff and guidelines, equipment, and medicines and commodities). Trained staff and guidelines had a readiness score of $27.5 \%(4 / 16)$ (Figure 1). It is the lowest domain score of BEmONC services, and only two facilities had all the tracer items. Relatively low trained staff and guideline readiness domain score was recorded among health facilities in Dabat district $(12 \%,<1 / 5)$, and rural setting health facilities $(17.5 \%, 1 / 8)$. The survey also revealed that threefourth of the health facilities lack essential newborn care guidelines, and more than $81 \%(13 / 16)$ of staff did not get training on essential childbirth in the past two years (Table 2).

The readiness score of equipment was $71.9 \%(12 / 16)$. All hospitals and most urban health facilities had the items in the domain. However, only two health facilities had all the domain items. Examination light, vacuum aspirator, and alcohol-based hand rub were available only in a quarter of health facilities. Besides, emergency transport and manual vacuum extractor were available among 
Table I Characteristics of Health Facilities, Northwest Ethiopia $(\mathrm{N}=16)$, March 2019

\begin{tabular}{|c|c|c|}
\hline Variables & Category & Frequency n (\%) \\
\hline \multirow[t]{3}{*}{ District } & Dabat & $5(3 \mid .2)$ \\
\hline & Debark & $7(43.8)$ \\
\hline & Janamora & $4(25.0)$ \\
\hline \multirow[t]{2}{*}{ Health facility type } & $\begin{array}{l}\text { Health } \\
\text { centers }\end{array}$ & 14 (87.5) \\
\hline & Hospitals & $2(12.5)$ \\
\hline \multirow[t]{2}{*}{ Place of health facility } & Urban & $8(50)$ \\
\hline & Rural & $8(50)$ \\
\hline \multicolumn{3}{|c|}{ Availability of healthcare workers } \\
\hline \multirow{2}{*}{$\begin{array}{l}\text { Generalist medical } \\
\text { doctors }\end{array}$} & No & $14(87.5)$ \\
\hline & $\begin{array}{l}\text { Yes } \\
\text { (hospitals) }\end{array}$ & $2(12.5)$ \\
\hline \multirow{4}{*}{$\begin{array}{l}\text { Specialist medical } \\
\text { doctors } \\
\text { Health officers }\end{array}$} & No & $16(100)$ \\
\hline & No & $3(18.8)$ \\
\hline & I or 2 & $7(43.7)$ \\
\hline & 3 or 4 & $6(37.5)$ \\
\hline \multirow[t]{3}{*}{ Midwives } & I or 2 & $5(3 \mid .2)$ \\
\hline & 3 or 4 & $7(43.7)$ \\
\hline & 5 or more & $4(25)$ \\
\hline \multirow[t]{2}{*}{ Nurses } & $2-5$ & $5(3 \mid .2)$ \\
\hline & $\begin{array}{l}6 \text { and } \\
\text { above }\end{array}$ & II (68.8) \\
\hline \multirow[t]{3}{*}{ Pharmacists } & No & $2(12.5)$ \\
\hline & One & $8(50)$ \\
\hline & $\begin{array}{l}\text { Two or } \\
\text { more }\end{array}$ & $6(37.5)$ \\
\hline \multirow[t]{3}{*}{ Laboratory technicians } & No & $7(43.7)$ \\
\hline & One & $6(37.5)$ \\
\hline & $\begin{array}{l}\text { Two or } \\
\text { more }\end{array}$ & $3(18.7)$ \\
\hline \multicolumn{3}{|c|}{ Availability of services and beds } \\
\hline \multirow{2}{*}{$\begin{array}{l}\text { Provision of inpatient } \\
\text { services }\end{array}$} & No & $10(62.5)$ \\
\hline & Yes & $6(37.5)$ \\
\hline \multirow{4}{*}{$\begin{array}{l}\text { Number of inpatient beds } \\
\text { (including pediatric beds) }\end{array}$} & No & $8(50)$ \\
\hline & 1 or 2 & $2(12.5)$ \\
\hline & 3 or 4 & $3(18.7)$ \\
\hline & 5 or more & $4(25)$ \\
\hline $\begin{array}{l}\text { Number of maternity } \\
\text { beds (excluding delivery } \\
\text { beds) }\end{array}$ & No & $3(18.7)$ \\
\hline
\end{tabular}

(Continued)
Table I (Continued).

\begin{tabular}{|l|l|l|}
\hline Variables & Category & Frequency n (\%) \\
\hline & I or 2 & $3(18.7)$ \\
3 or 4 & $5(31.2)$ \\
5 or more & $5(31.2)$ \\
\hline $\begin{array}{l}\text { Mean number of } \\
\text { outpatient visit per year }\end{array}$ & $\begin{array}{l}\text { Health } \\
\text { centers } \\
\text { Hospitals }\end{array}$ & $\begin{array}{l}\text { Min=1804, Max }=19,198) \\
44,507(S D=30,555, \\
\text { Min=22,90I, Max=66,II3) }\end{array}$ \\
\hline $\begin{array}{l}\text { The mean catchment } \\
\text { area of facilities }\end{array}$ & $\begin{array}{l}\text { Health } \\
\text { centers } \\
\text { Hospitals }\end{array}$ & $\begin{array}{l}\text { Min=10,132, Max=43,909) } \\
760,280(S D=1,046,122, \\
\text { Min=20,560, } \\
\text { Max=1.5 million) }\end{array}$ \\
& &
\end{tabular}

$43.8 \%(7 / 16)$ and $37.5 \%(6 / 16)$ health facilities, respectively.

Medicine and commodities readiness score was $88.6 \%$ (14/16), and half of the health facilities had all the domain items. All hospitals and most urban health facilities had the items in the domain. On the other hand, skin disinfectant, injectable uterotonic, antibiotic eye ointment, and intravenous solution with infusion sets were available in $75 \%$ (12/16), $81.3 \%$ (13/16), $87.5 \%$ (14/16), and $87.5 \%$ $(14 / 16)$ health facilities, respectively.

\section{Child Immunization Services Readiness Score}

The overall readiness of child immunization services among health facilities was $90.3 \%$ (15/16), and $68.8 \%$ $(11 / 16)$ health facilities had all the tracer items in the three domains (trained staff and guidelines, equipment, and medicines and commodities). Trained staff and guidelines had a readiness score of $84.4 \%$ (14/16) (Figure 2). However, child immunization services were ready for half $(2 / 4)$ of the health facilities in the Janamora district, and $75 \%(6 / 8)$ of the rural health facilities in the study area (Table 3).

The equipment readiness score was found to be $92.8 \%$ $(15 / 16)$. Unlike Debark district health facilities which had $100 \%(7 / 7)$ domain items, Janamora district health facilities lack one-third (1/4) of these domain items. The readiness score and mean availability of tracer items of medicines and commodities was 93.8\% (15/16). However, one-fourth (1/4) of the medicine and 


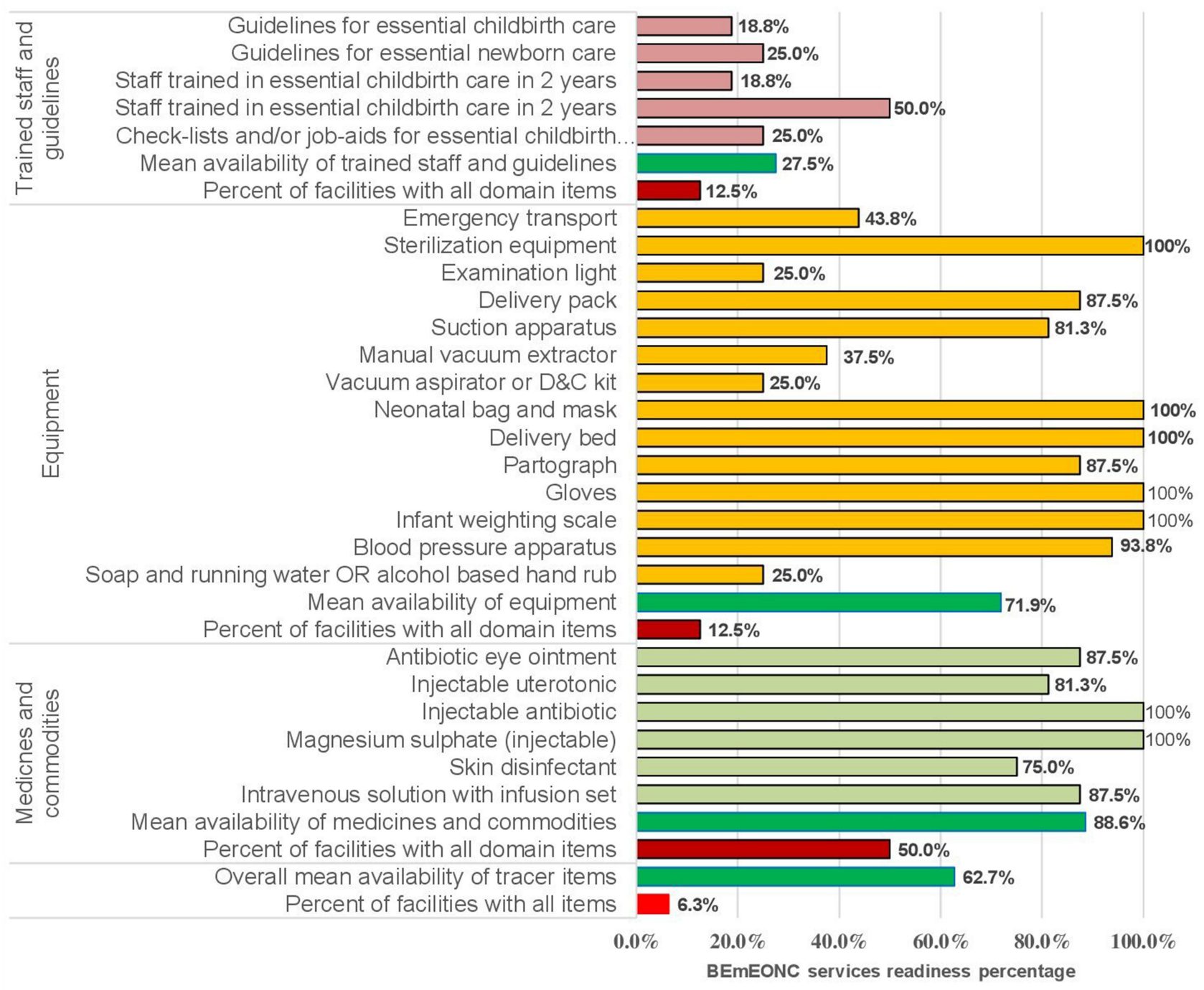

Figure I Health facilities BEmONC service readiness score in Northwest Ethiopia $(\mathrm{N}=16)$, March 2019.

commodities tracer items were lacking among health facilities in the Janamora district.

\section{Chi-Square Test}

Among health facilities, health centers had the lowest $(35.7 \%, 5 / 14)$ BEmONC service readiness score as compared to hospitals $(100 \%, 2 / 2)$, and this was statistically significant $(\mathrm{p}<0.05)($ Table 4$)$. Health facilities in urban areas had a $62.5 \%(5 / 8)$ BEmONC readiness score, and health facilities having six or more inpatient beds had a $100 \%(2 / 2)$ BEmONC readiness score $(p<0.05)$. Child immunization service readiness score was highest $(100 \%)$ for Dabat (5/5) and Debark (7/7) district health facilities, and low $(50 \%, 2 / 4)$ among health facilities in Janamora district $(\mathrm{p}<0.05)$. Health facilities providing healthcare for the community within the recommended catchment population size had full immunization readiness $(100 \%, 12 / 12)$ in the study area $(p<0.005)$.

\section{Barriers of Essential Newborn Care Service Provision}

The barriers of essential newborn services were thematized into two categories: health facility supply-side and healthcare workers (HCW) perspective.

\section{Health Facility Supply Side}

Lack of timely training for newly recruited staffs, unavailability of equipment (eg vacuum aspirator, delivery coach), shortage of medicines and commodities (eg Magnesium sulfate and BCG vaccine), and light 
Table 2 BEmONC Services Readiness Based on the Type of Health Facility, Administrative District, and Place of Health Facility in Northwest Ethiopia $(\mathrm{N}=16)$, March 2019

\begin{tabular}{|c|c|c|c|c|c|c|c|c|}
\hline \multirow[t]{2}{*}{ Characteristics } & \multirow[t]{2}{*}{$\begin{array}{l}\text { All Facilities } \\
\%(n=16)\end{array}$} & \multicolumn{2}{|c|}{$\begin{array}{l}\text { Type of Health } \\
\text { Facility }\end{array}$} & \multicolumn{3}{|c|}{ Administrative District } & \multicolumn{2}{|c|}{$\begin{array}{l}\text { Place of Health } \\
\text { Facility }\end{array}$} \\
\hline & & $\begin{array}{l}\text { HC \% } \\
(n=14)\end{array}$ & $\begin{array}{l}\text { Ho \% } \\
(n=2)\end{array}$ & $\begin{array}{c}\text { Dabat \% } \\
(n=5)\end{array}$ & $\begin{array}{l}\text { Debark } \\
\%(n=7)\end{array}$ & $\begin{array}{l}\text { Janamora } \\
\%(n=4)\end{array}$ & $\begin{array}{l}\text { Urban\% } \\
(n=8)\end{array}$ & $\begin{array}{c}\text { Rural \% } \\
(n=8)\end{array}$ \\
\hline \multicolumn{9}{|l|}{ Trained staff and guidelines } \\
\hline Guidelines for essential childbirth care & $18.8(3)$ & $14.3(2)$ & $\begin{array}{l}50.0 \\
(1)\end{array}$ & $0.0(0)$ & $28.6(2)$ & $25.0(1)$ & $25.0(2)$ & $12.5(1)$ \\
\hline Guidelines for essential newborn care & $25.0(4)$ & $21.4(3)$ & $\begin{array}{l}50.0 \\
(1)\end{array}$ & $20.0(1)$ & $28.6(2)$ & $25.0(1)$ & $37.5(3)$ & $12.5(1)$ \\
\hline $\begin{array}{l}\text { Staff trained in essential childbirth care } \\
\text { in the past two years }\end{array}$ & $18.8(3)$ & $14.3(2)$ & $\begin{array}{l}50.0 \\
(1)\end{array}$ & $0.0(0)$ & $42.9(3)$ & $0.0(0)$ & $25.0(2)$ & $12.5(1)$ \\
\hline $\begin{array}{l}\text { Staff trained in newborn resuscitation } \\
\text { in the past two years }\end{array}$ & $50.0(8)$ & $42.9(6)$ & $100(2)$ & $40.0(2)$ & $57.1(4)$ & $50.0(2)$ & $75.0(6)$ & $25.0(2)$ \\
\hline $\begin{array}{l}\text { Check-lists and/or job-aids for } \\
\text { essential child birth care }\end{array}$ & $25.0(4)$ & $21.4(3)$ & $\begin{array}{l}50.0 \\
(1)\end{array}$ & $0.0(0)$ & $42.9(3)$ & $25.0(1)$ & $25.0(2)$ & $25.0(2)$ \\
\hline Domain mean score & $27.5(4)$ & $\begin{array}{l}22.9 \\
(3)\end{array}$ & $60(1)$ & $\begin{array}{l}12.0 \\
(<1)\end{array}$ & $40.0(3)$ & $25.0(1)$ & $37.5(3)$ & $17.5(1)$ \\
\hline \multicolumn{9}{|l|}{ Equipment } \\
\hline Emergency transport & $43.8(7)$ & $35.7(5)$ & $100(2)$ & $40.0(2)$ & $42.9(3)$ & $50.0(2)$ & $75.0(6)$ & $12.5(1)$ \\
\hline Sterilization equipment & $100(16)$ & $100(14)$ & $100(2)$ & $100(5)$ & $100(7)$ & $100(4)$ & $100(8)$ & $100(8)$ \\
\hline Examination light & $25.0(4)$ & $14.3(2)$ & $100(2)$ & $100(5)$ & $28.6(2)$ & $50.0(2)$ & $37.5(3)$ & $12.5(1)$ \\
\hline Delivery pack & $87.5(14)$ & $\begin{array}{l}85.7 \\
(12)\end{array}$ & $100(2)$ & $80.0(4)$ & $100(7)$ & $75.0(3)$ & $100(8)$ & $75.0(6)$ \\
\hline Suction apparatus & $81.3(13)$ & $\begin{array}{l}78.6 \\
(11)\end{array}$ & $100(2)$ & $80.0(4)$ & $71.4(5)$ & $100(4)$ & $100(8)$ & $62.5(5)$ \\
\hline Manual vacuum extractor & $37.5(6)$ & $28.6(4)$ & $100(2)$ & $20.0(1)$ & $28.6(2)$ & $75.0(3)$ & $62.5(5)$ & $12.5(1)$ \\
\hline Vacuum aspirator & $25.0(4)$ & $14.3(2)$ & $100(2)$ & $0.0(0)$ & $28.6(2)$ & $50.0(2)$ & $37.5(3)$ & $12.5(1)$ \\
\hline Neonatal bag and mask & $100(16)$ & $100(14)$ & $100(2)$ & $100(5)$ & $100(7)$ & $100(4)$ & $100(8)$ & $100(8)$ \\
\hline Delivery bed & $100(16)$ & $100(14)$ & $100(2)$ & $100(5)$ & $100(7)$ & $100(4)$ & $100(8)$ & $100(8)$ \\
\hline Partograph & $87.5(14)$ & $\begin{array}{l}85.7 \\
(12)\end{array}$ & $100(2)$ & $100(5)$ & $71.4(5)$ & $100(4)$ & $100(8)$ & $75.0(6)$ \\
\hline Gloves & $100(16)$ & $100(14)$ & $100(2)$ & $100(5)$ & $100(7)$ & $100(4)$ & $100(8)$ & $100(8)$ \\
\hline Infant weighing scale & $100(16)$ & $100(14)$ & $100(2)$ & $100(5)$ & $100(7)$ & $100(4)$ & $100(8)$ & $100(8)$ \\
\hline Blood pressure apparatus & $93.8(15)$ & $\begin{array}{l}92.9 \\
(12)\end{array}$ & $100(2)$ & $80.0(4)$ & $100(7)$ & $100(4)$ & $87.5(7)$ & $100(8)$ \\
\hline Soap and running water & $25.0(4)$ & $14.3(2)$ & $100(2)$ & $0.0(0)$ & $28.6(2)$ & $50.0(2)$ & $37.5(3)$ & $12.5(1)$ \\
\hline Domain mean score & 71.9 (12) & $\begin{array}{l}67.9 \\
(10)\end{array}$ & $\begin{array}{l}100 \\
(2)\end{array}$ & $71.4(4)$ & $71.4(5)$ & $82.1(3)$ & $81.3(7)$ & $62.5(5)$ \\
\hline
\end{tabular}

(Continued) 
Table 2 (Continued).

\begin{tabular}{|c|c|c|c|c|c|c|c|c|}
\hline \multirow[t]{2}{*}{ Characteristics } & \multirow[t]{2}{*}{$\begin{array}{l}\text { All Facilities } \\
\%(n=16)\end{array}$} & \multicolumn{2}{|c|}{$\begin{array}{l}\text { Type of Health } \\
\text { Facility }\end{array}$} & \multicolumn{3}{|c|}{ Administrative District } & \multicolumn{2}{|c|}{$\begin{array}{l}\text { Place of Health } \\
\text { Facility }\end{array}$} \\
\hline & & $\begin{array}{l}\mathrm{HC} \% \\
(n=14)\end{array}$ & $\begin{array}{l}\text { Ho \% } \\
(n=2)\end{array}$ & $\begin{array}{c}\text { Dabat \% } \\
(n=5)\end{array}$ & $\begin{array}{l}\text { Debark } \\
\%(n=7)\end{array}$ & $\begin{array}{l}\text { Janamora } \\
\%(n=4)\end{array}$ & $\begin{array}{l}\text { Urban\% } \\
(n=8)\end{array}$ & $\begin{array}{c}\text { Rural \% } \\
(n=8)\end{array}$ \\
\hline \multicolumn{9}{|l|}{ Medicines and commodities } \\
\hline Antibiotic eye ointment & $87.5(14)$ & $\begin{array}{l}85.7 \\
(12)\end{array}$ & $100(2)$ & $100(4)$ & $85.7(6)$ & $75.0(3)$ & $100(8)$ & $75.0(6)$ \\
\hline Injectable uterotonic & $81.3(13)$ & $\begin{array}{l}78.6 \\
(11)\end{array}$ & $100(2)$ & $80.0(4)$ & $85.7(6)$ & $75.0(3)$ & $75.0(6)$ & $87.5(7)$ \\
\hline Injectable antibiotic & $100(16)$ & $100(14)$ & $100(2)$ & $100(4)$ & $100(7)$ & $100(4)$ & $100(8)$ & $100(8)$ \\
\hline Magnesium sulphate & $100(16)$ & $100(14)$ & $100(2)$ & $100(4)$ & $100(7)$ & $100(4)$ & $100(8)$ & $100(8)$ \\
\hline Skin disinfectant & $75(12)$ & $\begin{array}{l}71.4 \\
(10)\end{array}$ & $100(2)$ & $60.0(3)$ & $71.4(5)$ & $100(4)$ & $87.5(7)$ & $62.5(5)$ \\
\hline Intravenous solution with infusion set & $87.5(14)$ & $\begin{array}{l}85.7 \\
(12)\end{array}$ & $100(2)$ & $60.0(3)$ & $71.4(5)$ & $100(4)$ & $75.0(6)$ & $100(8)$ \\
\hline Domain mean score & $88.6(14)$ & $\begin{array}{l}87.0 \\
(12)\end{array}$ & $\begin{array}{l}100 \\
(2)\end{array}$ & $83.3(4)$ & $72.9(6)$ & $91.7(4)$ & 89.6 (7) & $87.5(7)$ \\
\hline $\begin{array}{l}\text { Overall mean availability of tracer } \\
\text { items }\end{array}$ & $62.7(10)$ & $\begin{array}{l}59.3 \\
(8)\end{array}$ & $\begin{array}{l}86.7 \\
(2)\end{array}$ & $55.6(3)$ & $61.4(5)$ & $66.3(2)$ & $69.5(6)$ & $55.8(4)$ \\
\hline Percent of facilities with all items & $6.3(1)$ & $0.0(0)$ & $\begin{array}{l}50.0 \\
\text { (I) }\end{array}$ & $0.0(0)$ & 14.3 (I) & $0.0(0)$ & $12.5(1)$ & $0.0(0)$ \\
\hline
\end{tabular}

interruption were health facility-related barriers to uptake BEmONC and child immunization services in the study area. Lack of timely training was among the repeatedly reported barriers to the provision of essential newborn services. Most of the surveyed health facilities are relatively distant and suffer from high staff turn-over.

A 28-year-old MCH focal person, and key informant interviewee, in the Janamora district, said; "Lack of timely training for newly employed staff was the most common barrier for them to provide appropriate BEmONC services."

BEmONC services need various equipment; including an electrical vacuum aspirator, and delivery coaches, for appropriate essential newborn care service provision. A 35 years old female BSc nurse key informant interviewee expressed, "I could not give quality BEmONC services, because the electrical vacuum aspirator is not working, and the delivery coach is outdated."

BEmONC and child immunization needs medicines and commodities. Unavailability of magnesium sulfate and $\mathrm{BCG}$ vaccine were the most frequently reported items.

A midwife with eight years of experience and who was an EPI focal person key informant interviewee said,

I could not believe that we are providing full immunizations schedules, because BCG vaccine is not timely available, and some antigens supplied lately. This affects full immunization coverage and wastage of antigens due to late supply of antigens.

She also added that "Magnesium sulfate is mostly unavailable in our health facility, leading to life-threatening conditions to the neonate and the mother."

Light interruption affects the essential newborn care services by disturbing the cold chain process. A 28 -yearold EPI focal person shared,

I do not believe that the quality of BCG and other antigens, which need cold chain is good, because it would be disrupted by the frequent light interruption and may lose its effectiveness. 


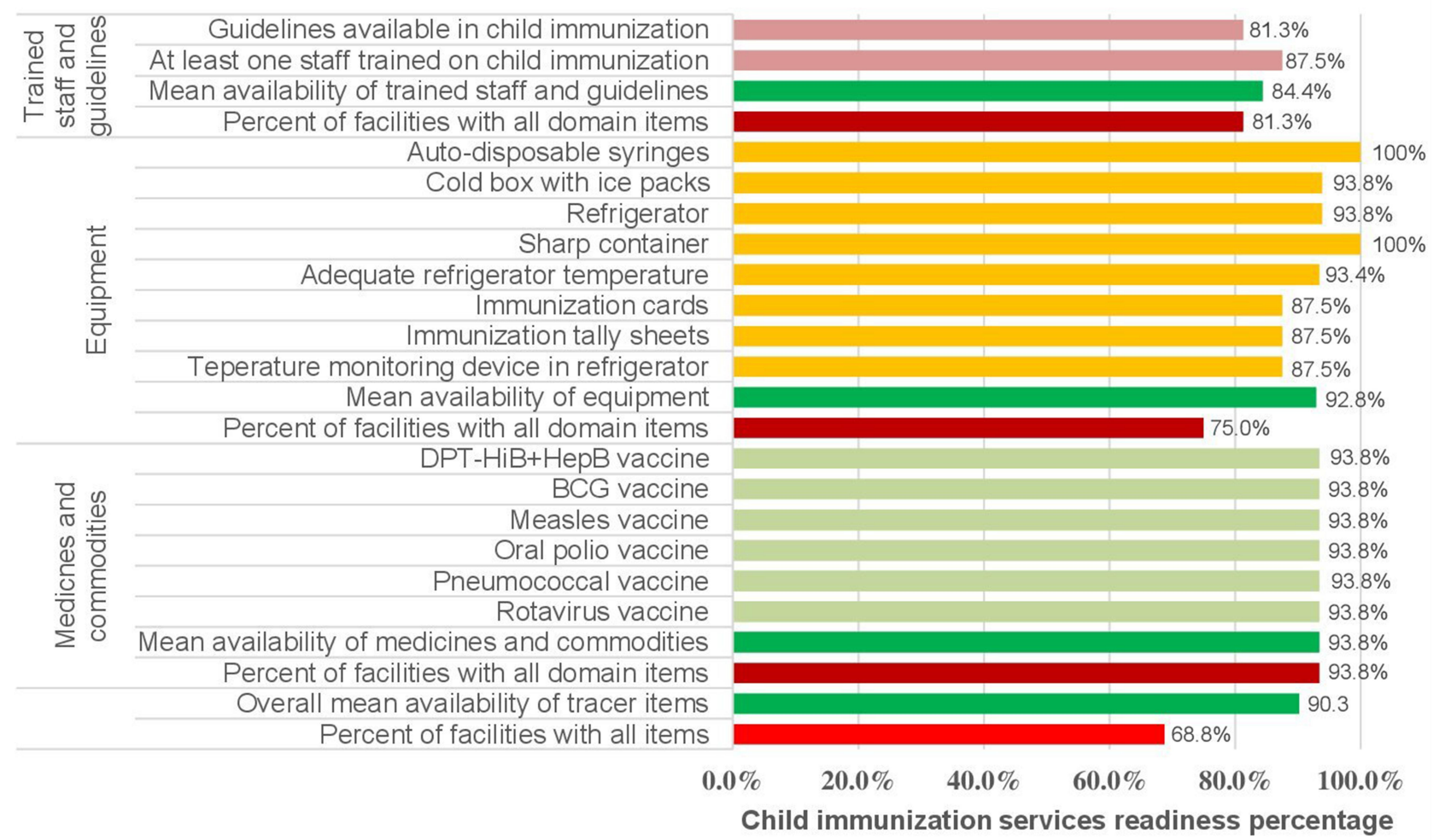

Figure 2 Health facilities child immunization service readiness score in Northwest Ethiopia (N=16), March 2019.

\section{Healthcare Workers' Perspective}

Poor customer handling or poor caring, respectful, and compassionate (CRC) healthcare practices, poor teamwork, and delegation practice were the barriers from the HCWs side.

A midwife with six years of experience and who was a key informant interviewee affirmed,

In my experience and observation, most HCWs had poor customer handling and they did not adhere to CRC principles during BEmONC and child immunization service provisions. Lack of teamwork and delegation system for tasks under certain circumstances is a problem.

\section{Discussion}

This study was designed to determine the essential newborn care service readiness scores and to explore the health facility-related barriers of newborn care in Northwest Ethiopia. Subsequently, the overall BEmONC service readiness score was $62.7 \%(10 / 16)$, and $90.3 \%$ (15/ 16) overall readiness score was recorded for child immunization services. Lack of timely training for newly recruited staff, unavailability of equipment (eg vacuum aspirator, delivery coach), shortage of medicines and commodities (eg Magnesium sulfate and BCG vaccine), and light interruption emerged as health facility-related barriers. Poor customer handling, lack of respectful and compassionate (CRC) healthcare practices, poor teamwork, and poor delegation practices were the barriers from the HCW's side.

The overall readiness score to provide BEmONC in Northwest Ethiopia was lower than the national figure and other similar studies in Low and Middle-Income Countries (LMIC). ${ }^{10,14-18}$ The $62.7 \%(10 / 16)$ overall BEmONC service readiness score refers to the fact that only $62.7 \%$ of all facilities in the study area were ready to provide $\mathrm{BEmONC}$ as per the WHO requirements ${ }^{13}$ such as trained staff and guidelines, equipment, and medicines and commodities. There is only one health facility which had all the tracer items as per WHO guideline. Lack of trained staff and equipment could be the possible explanations for the disparity. The key informant interview finding also argued that there is a gap in timely training for newly employed staff, CRC healthcare, and teamwork practices, which might have implications to the health system.

BEmONC service readiness score was higher in hospitals rather than health centers, and this finding was 
Table 3 Child Immunization Services Readiness Based on the Type of Health Facility, Administrative District, and Place of Health Facility in Northwest Ethiopia ( $\mathrm{N}=16)$, March 2019

\begin{tabular}{|c|c|c|c|c|c|c|c|c|}
\hline \multirow[t]{2}{*}{ Characteristics } & \multirow[t]{2}{*}{$\begin{array}{l}\text { All Facilities } \\
\%(n=16)\end{array}$} & \multicolumn{2}{|c|}{$\begin{array}{l}\text { Type of Health } \\
\text { Facility }\end{array}$} & \multicolumn{3}{|c|}{ Administrative District } & \multicolumn{2}{|c|}{$\begin{array}{c}\text { Place of Health } \\
\text { Facility }\end{array}$} \\
\hline & & $\begin{array}{l}\mathrm{HC} \% \\
(n=14)\end{array}$ & $\begin{array}{l}\text { Ho \% } \\
(n=2)\end{array}$ & $\begin{array}{c}\text { Dabat \% } \\
(n=5)\end{array}$ & $\begin{array}{l}\text { Debark \% } \\
\qquad(n=7)\end{array}$ & $\begin{array}{c}\text { Janamora } \\
\%(n=4)\end{array}$ & $\begin{array}{l}\text { Urban\% } \\
(n=8)\end{array}$ & $\begin{array}{c}\text { Rural \% } \\
(\mathbf{n}=\mathbf{8})\end{array}$ \\
\hline \multicolumn{9}{|l|}{ Trained staff and guidelines } \\
\hline $\begin{array}{l}\text { Guidelines available in child } \\
\text { immunization }\end{array}$ & $81.3(13)$ & $78.6(11)$ & $100(2)$ & $80.0(4)$ & $100(7)$ & $50.0(2)$ & $87.5(7)$ & $75.0(6)$ \\
\hline $\begin{array}{l}\text { At least one staff trained on child } \\
\text { immunization }\end{array}$ & $87.5(14)$ & $85.7(12)$ & $100(2)$ & $100(5)$ & $100(7)$ & $50.0(2)$ & $100(8)$ & $75.0(6)$ \\
\hline Domain mean score & $84.4(14)$ & $\begin{array}{l}82.2 \\
(12)\end{array}$ & $\begin{array}{l}100 \\
(2)\end{array}$ & $90.0(5)$ & $100(7)$ & $50.0(2)$ & $93.8(8)$ & $75.0(6)$ \\
\hline \multicolumn{9}{|l|}{ Equipment } \\
\hline Auto-disposable syringes & $100(16)$ & $100(16)$ & $100(2)$ & $100(5)$ & $100(7)$ & $100(2)$ & $100(8)$ & $100(8)$ \\
\hline Cold box with ice packs & $93.4(15)$ & $92.9(13)$ & $100(2)$ & $100(5)$ & $100(7)$ & $75.0(3)$ & $100(8)$ & $87.5(7)$ \\
\hline Refrigerator & $93.4(15)$ & $92.9(13)$ & $100(2)$ & $100(5)$ & $100(7)$ & $75.0(3)$ & $100(8)$ & $87.5(7)$ \\
\hline Sharps container & $100(16)$ & $100(16)$ & $100(2)$ & $100(5)$ & $100(7)$ & $100(2)$ & $100(8)$ & $100(8)$ \\
\hline $\begin{array}{l}\text { Adequate refrigerator } \\
\text { temperature }\end{array}$ & $93.4(15)$ & $92.9(13)$ & $100(2)$ & $100(5)$ & $100(7)$ & $75.0(3)$ & $100(8)$ & $87.5(7)$ \\
\hline Immunization cards & $87.5(14)$ & $92.9(13)$ & $50.0(1)$ & $100(5)$ & $100(7)$ & $50.0(2)$ & $87.5(7)$ & $87.5(7)$ \\
\hline Immunization tally sheets & $87.5(14)$ & $85.7(12)$ & $100(2)$ & $100(5)$ & $100(7)$ & $50.0(2)$ & $100(8)$ & $75.0(6)$ \\
\hline $\begin{array}{l}\text { The temperature monitoring } \\
\text { device in a refrigerator }\end{array}$ & $87.5(14)$ & $85.7(12)$ & $100(2)$ & $80.0(4)$ & $100(7)$ & $75.0(3)$ & $87.5(7)$ & $87.5(7)$ \\
\hline Domain mean score & $92.8(15)$ & $\begin{array}{l}92.9 \\
(13)\end{array}$ & $\begin{array}{c}93.8 \\
(2)\end{array}$ & $97.5(5)$ & $100(7)$ & $75.0(3)$ & $96.9(8)$ & $89.1(7)$ \\
\hline \multicolumn{9}{|l|}{ Medicines and commodities } \\
\hline DPT-HiB+HepB vaccine & $93.8(15)$ & $92.9(13)$ & $100(2)$ & $100(5)$ & $100(7)$ & $75.0(3)$ & $100(8)$ & $87.5(7)$ \\
\hline$B C G$ vaccine & $93.8(15)$ & $92.9(13)$ & $100(2)$ & $100(5)$ & $100(7)$ & $75.0(3)$ & $100(8)$ & $87.5(7)$ \\
\hline Measles vaccine & $93.8(15)$ & $92.9(13)$ & $100(2)$ & $100(5)$ & $100(7)$ & $75.0(3)$ & $100(8)$ & $87.5(7)$ \\
\hline Oral polio vaccine & $93.8(15)$ & $92.9(13)$ & $100(2)$ & $100(5)$ & $100(7)$ & $75.0(3)$ & $100(8)$ & $100(8)$ \\
\hline Pneumococcal vaccine & $93.8(15)$ & $92.9(13)$ & $100(2)$ & $100(5)$ & $100(7)$ & $75.0(3)$ & $100(8)$ & $87.5(7)$ \\
\hline Rotavirus vaccine & $93.8(15)$ & $92.9(13)$ & $100(2)$ & $100(5)$ & $100(7)$ & $75.0(3)$ & $100(8)$ & $87.5(7)$ \\
\hline Domain mean score & $93.8(15)$ & $92.9(13)$ & $100(2)$ & $100(5)$ & $100(7)$ & $75.0(3)$ & $100(8)$ & $89.6(7)$ \\
\hline $\begin{array}{l}\text { Mean availability of tracer } \\
\text { items }\end{array}$ & $90.3(15)$ & $89.3(13)$ & $97.9(2)$ & $95.8(5)$ & $100(7)$ & $66.7(3)$ & $96.9(8)$ & $84.6(7)$ \\
\hline $\begin{array}{l}\text { Percent of facilities with all } \\
\text { items }\end{array}$ & $68.8(11)$ & $71.4(10)$ & $50.0(1)$ & $60.0(3)$ & $100(7)$ & $25.0(1)$ & $62.5(5)$ & $75.0(6)$ \\
\hline
\end{tabular}


Table 4 BEmONC and Child Immunization Services Readiness Scores Among Health Facilities in Northwest Ethiopia (16), March 2019

\begin{tabular}{|c|c|c|c|c|c|c|c|c|}
\hline \multirow[t]{2}{*}{ Variable } & \multicolumn{3}{|c|}{ BEmONC Readiness } & \multirow[t]{2}{*}{$p$-value } & \multicolumn{3}{|c|}{ Child Immunization Readiness } & \multirow[t]{2}{*}{$p$-value } \\
\hline & Yes (\%) & No (\%) & Total & & Yes (\%) & No (\%) & Total & \\
\hline \multicolumn{9}{|c|}{ Administrative district } \\
\hline Dabat & I (20) & $4(80)$ & 5 & 0.423 & $5(100)$ & $0(0)$ & 5 & $0.032 *$ \\
\hline Debark & $4(57.1)$ & $3(42.9)$ & 7 & & $7(100)$ & $0(0)$ & 7 & \\
\hline Janamora & $2(50)$ & $2(50)$ & 4 & & $2(50)$ & $2(50.0)$ & 4 & \\
\hline \multicolumn{9}{|l|}{ Facility type } \\
\hline Hospitals & $2(100)$ & $0(0)$ & 2 & $0.001 * *$ & $2(100)$ & $0(0)$ & 2 & 0.568 \\
\hline Health centers & $5(35.7)$ & $9(64.3)$ & 14 & & $12(85.7)$ & $2(12.5)$ & 14 & \\
\hline \multicolumn{9}{|l|}{ Facility location } \\
\hline Urban & $5(62.5)$ & $3(37.5)$ & 8 & $0.045^{*}$ & $8(100)$ & $0(0)$ & 8 & 0.131 \\
\hline Rural & $2(25)$ & $6(75)$ & 8 & & $6(75)$ & $2(25)$ & 8 & \\
\hline \multicolumn{9}{|c|}{ Provision of inpatient services } \\
\hline No & $3(30)$ & $7(70)$ & 10 & 0.152 & $8(80)$ & $2(20)$ & 10 & 0.242 \\
\hline Yes & $4(66.7)$ & $2(33.3)$ & 6 & & $6(100)$ & $0(0)$ & 6 & \\
\hline \multicolumn{9}{|c|}{ Number of inpatient beds } \\
\hline $0-5$ beds & $5(35.7)$ & $9(64.3)$ & 14 & $0.015^{*}$ & $12(85.7)$ & $2(14.3)$ & 14 & 0.568 \\
\hline$\geq 6$ beds & $2(100)$ & $0(0)$ & 2 & & $2(100)$ & $0(0)$ & 2 & \\
\hline \multicolumn{9}{|c|}{ Newborn deaths from random deliveries } \\
\hline No & $4(40)$ & $6(60)$ & 10 & 0.696 & $9(90)$ & I (10) & 10 & 0.719 \\
\hline Yes & $3(50)$ & $3(50)$ & 6 & & $5(83.3)$ & I (16.7) & 6 & \\
\hline \multicolumn{9}{|c|}{ Number of newborn illnesses from random deliveries } \\
\hline Five or less & $3(33.3)$ & $6(66.7)$ & 9 & $0.34 I$ & $8(88.9)$ & $\mathrm{I}(\mathrm{II} . \mathrm{I})$ & 9 & 0.849 \\
\hline Six or more & $4(57.1)$ & $3(42.9)$ & 7 & & $6(85.7)$ & I (I4.3) & 7 & \\
\hline \multicolumn{9}{|c|}{ Facility overall newborn care quality during delivery (mean=66.3\%) } \\
\hline Below the mean & $3(75)$ & $\mathrm{I}(25)$ & 4 & 0.303 & $3(75)$ & $\mathrm{I}(25)$ & 4 & 0.658 \\
\hline Mean and above & $3(42.9)$ & $4(57.1)$ & 7 & & $6(85.7)$ & I (14.3) & 7 & \\
\hline \multicolumn{9}{|c|}{ Number of outpatient visits per year } \\
\hline$<$ Standard deviation & $5(55.6)$ & $4(44.4)$ & 9 & 0.280 & $7(77.8)$ & $2(22.2)$ & 9 & $0.003^{*}$ \\
\hline$\geq$ Standard deviation & $2(28.6)$ & $5(7 \mid .4)$ & 7 & & $7(100)$ & $0(0)$ & 7 & \\
\hline \multicolumn{9}{|c|}{ The mean catchment area of facilities } \\
\hline Within the standard & $6(50)$ & $6(50)$ & 12 & 0.383 & $12(100)$ & $0(0)$ & 12 & $0.005^{*}$ \\
\hline Above the standard & $\mathrm{I}(25)$ & $3(75)$ & 4 & & $2(50)$ & $2(50)$ & 4 & \\
\hline
\end{tabular}

Note: $*_{p}<0.05$, and $* * p<0.01$.

supported by similar studies in Bangladesh, Madagascar, and Tanzania. ${ }^{15,16,18}$ Arguably, equipment, medicines, and commodities are relatively available in hospitals. The availability of equipment and supplies could lead to high patient flow, this would help for the retention of complex skills of healthcare workers, and these all issues could attribute to a better hospital BEmONC service readiness score. $^{19}$ 
Trained staff and guidelines availability level for BEmONC was the lowest domain score $(27.5 \%, 4 / 16)$. This indicates that the majority of the health facilities lack BEmONC trained staff and guidelines, which might have a detrimental impact on the quality of care and neonatal outcome. A similar study in Nepal also indicated that it was the lowest domain score, but the real figure was higher $(51.3 \%)$ than the current finding. ${ }^{14}$ The difference could be due to variations in the curricula of health education, distribution of guidelines, and the healthcare system.

Only $18.8 \%(3 / 16)$ of the health facilities had staff trained in essential childbirth care in the past two years in 2019, which is a little higher than the previous studies done in Ethiopia. ${ }^{20,21}$ However, the national Health Sector Development Programme (HSDP) for the year 2010 to 2015 has given the focus on developing critical workforce skills for improving the quality of healthcare in Ethiopia with due emphasis on standard in-service training. ${ }^{22}$ Hence, BEmONC staffs among health facilities in Northwest Ethiopia are behind the national HSDP and WHO guidelines, ${ }^{13,22}$ which might disturb the reduction of child mortality and morbidity of the study area.

Besides, only $25 \%(4 / 16)$ of the assessed health facilities had important equipment such as examination light, vacuum aspirator or D\&C kit, soap, and running water or alcohol-based hand rub. This indicates that only onequarter of the health facilities in the study area could provide basic preventive care using soap and running water during delivery. However, a similar study in Bangladesh and Nepal showed that more than $80 \%$ of the health facilities had essential equipment. ${ }^{14,16}$ The absence of such equipment has a clear effect on screening services during childbirth care. This was a common challenge identified by other studies. ${ }^{23}$ The lack of progress through time entails further concerted efforts by district health offices, health facility administration, healthcare workers, and other stakeholders. Furthermore, the unavailability of equipment (eg vacuum aspirator, delivery coach), shortage of medicines, and commodities (eg Magnesium sulfate) might also contribute to the variation in the study area.

This study revealed that the child immunization service readiness score was $90.3 \%(15 / 16)$, and two-third of the facilities $(68.8 \%, 11 / 16)$ had all the tracer items for child immunization services. This finding was supported by a similar study in Bangladesh. ${ }^{24}$ On the other hand, the current study finding was higher than the findings of the national SARA in Ethiopia. ${ }^{10}$ This figure was higher in health centers and a half for hospitals in Mongolia. ${ }^{25}$ This could be due to the similarity of the assessment methods as recommended by the SARA reference manual, ${ }^{26}$ differences in the healthcare system, and progress through time. Assessing the readiness of health facilities provide information for effective healthcare systems management. ${ }^{27}$

Unlike BEmONC, Child immunization service readiness scores were relatively higher for all components. This finding is congruent with the national assessment finding ${ }^{10}$ but lower than a similar study in Bangladesh, ${ }^{24}$ and higher than another study in Mongolia. ${ }^{25}$ This could be attributed to high government attention and mass immunization campaigns.

The provision of healthcare services within the recommended catchment population size was associated with having an immunization readiness score in the study area $(p<0.005)$. This was supported by another study in Nepal, where a disproportionate increase in delivery care in large hospitals in comparison to peripheral health facilities compromised by overcrowding and poor readiness to support the influx of clients. ${ }^{28}$ Similarly, health facilities in urban areas were associated with good BEmONC service readiness scores as compared to rural setting health facilities. A similar study also argued that in peripheral health facilities, the retention of complex skills, such as the resuscitation of patients, remains a challenge due to low client flow. ${ }^{19}$

This study provides evidence on the essential newborn care service readiness scores in a cross-sectional survey of Northwest Ethiopian health facilities. Many health centers and rural area facilities lacked readiness for essential newborn care services. Essential newborn care is essential not only for the survival of newborns but also for enabling them to have a better quality of life by preventing avoidable illnesses through an effective healthcare system. ${ }^{27}$ Improved newborn and child survival would help to thrive to the full potential of all children resulting in economic benefits for a nation. ${ }^{29}$ Therefore, developing a strategy that addresses the poor readiness score, and empowering the facility healthcare management system to oversee its implementation is crucially important for sustaining improvements.

This study was undertaken with the following limitations. First, due to resource limitations, the authors could not include health facilities from multiple administrative zones of the country to generalize the findings at regional and national levels. Second, the sample size of the 
surveyed health facilities was very small to make a quantitative analysis; however, as a mixed-method study, data from the key informant interview were used to support and cross-validate the survey findings.

\section{Conclusions}

This study confirmed that the essential newborn care service readiness score of the health facilities was low in Northwest Ethiopia. Both BEmONC and child immunization services lack full readiness in most health facilities and thus, many neonates did not receive all the essential newborn care services (poor readiness). Hence, improving the functional capacity or readiness level of health facilities; including the provision of in-service training to healthcare workers, and fulfilling essential equipment and supplies is imperative to improve neonatal survival.

\section{Data Sharing Statement}

The dataset that supports the findings of this study is available from the corresponding author upon reasonable request.

\section{Ethics Approval}

Before the commencement of data collection, ethical clearance was obtained from the Institutional Review Board (IRB) of the University of Gondar (UoG) (Ethics ID: O/V/ $\mathrm{P} / \mathrm{RCS} / 05 / 1818 / 2018$ ), and permission letters were secured from districts and health institution officials. During data collection, the health facility officials were consulted and an agreement on consent forms was signed.

\section{Acknowledgments}

The authors thank all the study participants, interviewers, local administrations, language editors, and WHO/EMPIC Project for funding this research project.

\section{Author Contributions}

All authors made substantial contributions to conception and design, acquisition of data, or analysis and interpretation of data; took part in drafting the article or revising it critically for important intellectual content; agreed to submit to the current journal; gave final approval of the version to be published; and agree to be accountable for all aspects of the work.

\section{Funding}

This work was supported by the World Health Organization (WHO) (Sub-grant $=$ OPP1109076).

\section{Disclosure}

The authors report no conflicts of interest for this work.

\section{References}

1. United Nations Inter-agency Group (UN IGME). Levels and Trends in Child Mortality Estimation by UNICEF, WHO, World Bank, UN-DESA Population Division, WHO; 2019.

2. Ethiopia Demographic and Health Survey (EDHS). Key Indicators Report. Central Statistical Agency, Addis Ababa, Ethiopia, and The DHS Program, ICF Rockville, Maryland, USA; 2019.

3. Mkoka DA, Goicolea I, Kiwara A, Mwangu M, Hurtig AK. Availability of drugs and medical supplies for emergency obstetric care: experience of health facility managers in a rural District of Tanzania. BMC Pregnancy Childbirth. 2014;14(1):108. doi:10.1186/ 1471-2393-14-108

4. Rana TG, Chataut BD, Shakya G, Nanda G, Pratt A, Sakai S. Strengthening emergency obstetric care in Nepal: the women's right to life and health project (WRLHP). Int J Gynaecol Obstet. 2007;98 (3):271-277. doi:10.1016/j.ijgo.2007.05.017

5. WHO, UNFPA, UNICEF, \& AMDD. Monitoring Emergency Obstetric Care: A Handbook. Geneva: World Health Organization; 2009.

6. Paxton A, Bailey P, Lobis S. The United Nations process indicators for emergency obstetric care: reflections based on a decade of experience. Int $J$ Gynaecol Obstet. 2006;95(2):192-208. doi:10.1016/j.ijgo.2006.08.009

7. Lawn JE, Kinney M, Lee AC, et al. Reducing intrapartum-related deaths and disability: can the health system deliver? Int J Gynaecol Obstet. 2009;107(1):123-142. doi:10.1016/j.ijgo.2009.07.021

8. Ministry of Health, Federal Democratic Republic of Ethiopia. Health Sector Transformation Plan (HSTP) 2015/16-2019/20. Addis Ababa Ethiopia; 2015.

9. Primary health care systems (PRIMASYS). A case study from Ethiopia, abridged version. Geneva: World Health Organization; 2017. License: CC BY-NC-SA 3.0 IGO.

10. Ethiopia Service Availability and Readiness Assessment Summary Report 2016. Addis Ababa, Ethiopia: Ethiopian Public Health Institute, Federal Ministry of Health, World Health Organization (WHO); January, 2017.

11. Tadesse GD, Gashaw AB, Solomon MA, Zemene TK. Common neonatal illnesses in Northwest Ethiopia: a Repeated Cross-Sectional Study. Plos ONE. In press 2021.

12. Central Statistical Agency [Ethiopia] and ICF International. Ethiopia demographic and health survey. Addis Ababa, Ethiopia, and Calverton, Maryland, USA: Central Statistical Agency and ICF International; 2016.

13. WHO Document Production Services. Service Provision and Readiness Assessment Tool. Organization WH, editor. Geneva: World Health Organization;2013.

14. Amrit B, Padam S, Edwin van T, et al. The availability of emergency obstetric care in birthing centres in Rural Nepal: a cross-sectional survey. Matern Child Health J. 2019;24:806-816. doi:10.1007/ s10995-019-02832-2

15. Bintabara D, Ernest A, Mpondo B. Health facility service availability and readiness to provide basic emergency obstetric and newborn care in a low-resource setting: evidence from a Tanzania National Survey. BMJ Open. 2019;9(2):e020608. doi:10.1136/bmjopen-2017-020608

16. Ashish KC, Dipendra RS, Madan KU, Shyam SB, Abhishek G, Mats M. Quality of care for maternal and newborn health in health facilities in Nepal. Matern Child Health J. 2019. doi:10.1007/s10995-019-02846-w

17. Kanyangarara M, Chou VB, Creanga AA, Walker N. Linking household and health facility surveys to assess obstetric service availability, readiness, and coverage: evidence from 17 low- and middle-income countries. J Glob Health. 2018;8(1):010603. doi:10.7189/ jogh.08.010603 
18. Andriantsimietry SH, Rakotomanga R, Rakotovao JP, et al. Service availability and readiness assessment of maternal, newborn, and child health services at public health facilities in Madagascar. Afr J Reprod Health. 2016;20(3):149-158. doi:10.29063/ajrh2016/v20i3.19

19. Dickson KE, Simen-Kapeu A, Kinney MV, et al. Every Newborn: health systems bottlenecks and strategies to accelerate scale-up in countries. Lancet. 2014;384(9941):438-454. doi:10.1016/S01406736(14)60582-1

20. Alemnesh HM, Mitike MS, Alemnesh TR, Mulu MB. Current evidence on basic emergency obstetric and newborn care services in Addis Ababa, Ethiopia; a cross-sectional study. BMC Pregnancy Childbirth. 2014;14:354. doi:10.1186/1471-2393-14-354

21. Keseteberhan A, Abonesh HM, Patricia B. Indicators for availability, utilization, and quality of emergency obstetric care in Ethiopia Int J Gynaecol Obstet. 2011. Published by Elsevier Ireland Ltd. All rights reserved. doi:10.1016/j.ijgo.2011.07.010.

22. FMOH. Health Sector Development Programme IV (HSDP IV). Addis Ababa: Federal Ministry of Health; 2010.

23. Jahn A, Dar IM, Shah U, Diesfeld HJ. Maternity care in rural Nepal: a health service analysis. Trop Med Int Health. 2000;5(9):657-665. doi:10.1046/j.1365-3156.2000.00611.x

24. Shajedur RS, Gourab A, Wazed A, et al. General service and child immunization specific readiness assessment of healthcare facilities in two selected divisions in Bangladesh. BMC Health Serv Res. 2018;18:39. doi:10.1186/s12913-018-2858-7
25. Altantuya J, Tumurbat B, Enkhjargal A, et al. Free and universal access to primary healthcare in Mongolia: the service availability and readiness assessment. BMC Health Serv Res. 2019;19:129. doi:10.1186/s12913-019-3932-5

26. World Health Organization (WHO). Service Availability and Readiness Assessment (SARA): an annual monitoring system for service delivery. Reference Manual. Version 2.2. Geneva: WHO; 2015.

27. Raven J, Hofman J, Adegoke A, Van Den Broek N. Methodology and tools for quality improvement in maternal and newborn healthcare. Int $J$ Gynaecol Obstet. 2011;114(1):4-9. doi:10.1016/j. ijgo.2011.02.007

28. Ministry of Health and Population, Nepal. Responding to increased demand for institutional childbirths at referral hospitals in Nepal: situational analysis and emerging options. Kathmandu: Ministry of Health and Population, and ICF International; 2013.

29. United Nations. Global strategy for women's, children's, and adolescent's health 2016-2030. New York: United Nations; 2016.
Journal of Multidisciplinary Healthcare

\section{Publish your work in this journal}

The Journal of Multidisciplinary Healthcare is an international, peerreviewed open-access journal that aims to represent and publish research in healthcare areas delivered by practitioners of different disciplines. This includes studies and reviews conducted by multidisciplinary teams as well as research which evaluates the results or conduct of such teams or healthcare processes in general. The journal

\section{Dovepress}

covers a very wide range of areas and welcomes submissions from practitioners at all levels, from all over the world. The manuscript management system is completely online and includes a very quick and fair peer-review system. Visit http://www.dovepress.com/testimonials. php to read real quotes from published authors. 